BARBOSA, T.M. et al. A importância da água na avicultura. PUBVET, Londrina, V. 8, N. 19, Ed. 268, Art. 1785, Outubro, 2014.

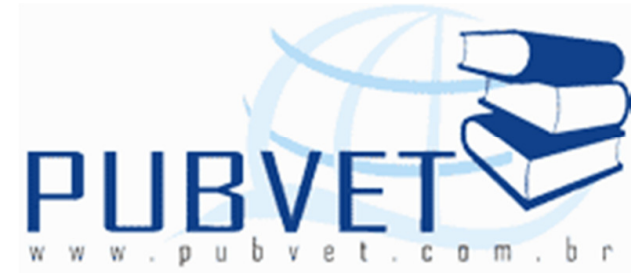

PUBVET, Publicações em Medicina Veterinária e Zootecnia.

\title{
A importância da água na avicultura
}

Tatiana Morais Barbosa, Frederico Lopes da Silva, Cássia Gabrielle de Queiróz Rodriz, Rodrigo Arruda de Oliveira, Rodrigo Diana Navarro, Angela Patrícia Santana, Luci Sayori Murata

Universidade de Brasília, Faculdade de Agronomia e Medicina Veterinária. Campus Universitário Darcy Ribeiro, Instituto Central de Ciências, Ala Sul, Asa Norte, CEP 70910-900, Brasília/ DF, Brasil. E-mail:tatiana.mrb@gmail.com

\section{Resumo}

Na avicultura deve-se dar à água a mesma importância a que se dá a outros fatores interativos com o animal como instalações, alimentação e manejo. As aves de produção necessitam de grande quantidade de água para seu desenvolvimento e bem-estar. Além da água para dessedentação, se deve considerar a água como insumo para o manejo da vacinação, limpeza, controle térmico do ambiente e desinfecção de equipamentos e instalações. Diversas variáveis interferem no consumo de água, entre elas a genética, a idade e sexo do animal, a temperatura do ambiente e da água, a umidade relativa do ar e a composição nutricional do alimento. A água é insubstituível para o organismo das aves, em virtude das funções que exerce no metabolismo, portanto é de fundamental importância o uso racional da água de boa qualidade física, química e microbiológica. Devido ao fato de as aves não possuírem glândulas sudoríparas para ajudar na dissipação de calor, o consumo de água fria é a 
BARBOSA, T.M. et al. A importância da água na avicultura. PUBVET, Londrina, V. 8, N. 19, Ed. 268, Art. 1785, Outubro, 2014.

alternativa que esses animais têm para diminuir a temperatura corporal em situações de estresse calórico. É incontestável que quando a ave possui disponibilidade de água em qualidade e quantidade adequadas, esta apresentará uma melhora no desempenho.

Palavras-chave: consumo de água; desempenho de aves; estresse térmico.

\section{Importance of water in poultry}

\section{Abstract}

In poultry industry should be given to water the same importance that is given to other factors such as facilities, feeding and management. Poultry production require large amounts of water for their development and welfare. Besides water for drinking, must also consider water as an input for the management of vaccination, cleaning, thermal control environment and disinfection of equipment and facilities. Several variables affect water consumption, including genetics, animal age, sex, ambient temperature, water temperature, the relative humidity and nutritional composition. Water is indispensable for life, because of the functions it plays in metabolism, so it is of fundamental importance to the rational use of water of good quality physical, chemical and microbiological. Because birds do not have sweat glands to aid in heat dissipation, the consumption of cold water is the alternative that these animals have to lower body temperature in situations of heat stress. It is undisputed that when the bird has water availability of adequate quality and quantity, this will present a performance improvement.

Keywords: performance of birds, thermal stress, water consumption.

\section{Introdução}

A produção animal, em seus diversos segmentos e modalidades, guarda relação direta com a disponibilidade de recursos hídricos. Na avicultura 
BARBOSA, T.M. et al. A importância da água na avicultura. PUBVET, Londrina, V. 8, N. 19, Ed. 268, Art. 1785, Outubro, 2014.

industrial há a necessidade da disponibilidade de água em quantidade e qualidade adequadas para atendimento de todos os setores da cadeia produtiva (OLIVEIRA, 2010). Para a produção, a campo, de $1 \mathrm{~kg}$ de carne de frango são necessários $8,2 \mathrm{~L}$ de água. Entretanto, o processo de industrialização dessa carne consome praticamente o dobro deste valor; o gasto no frigorífico de aves é de 16, 03 litros/kg de carne de frango (BELLAVER \& OLIVEIRA, 2009).

$\mathrm{Na}$ avicultura deve-se dar à água a mesma importância a que se dá a outros fatores como instalações, alimentação e manejo. As aves de produção necessitam de grande quantidade de água para seu desenvolvimento e bemestar (SOARES, 2010). Além da água para dessedentação, também se deve considerar a água como insumo para o manejo da vacinação, limpeza, controle térmico do ambiente e desinfecção de equipamentos e instalações (GAMA et al, 2008).

A água é insubstituível para o organismo das aves, em virtude das funções que ela exerce no metabolismo e a medida do consumo diário tornouse parâmetro de saúde e bem estar (PENZ, 2003). É um nutriente essencial e consumido em grande quantidade, portanto é de fundamental importância o uso racional da água de boa qualidade física, química e microbiológica (AMARAL, 2004).

O objetivo deste trabalho foi evidenciar a importância da água para o desempenho e bem estar das aves comerciais, bem como destacar as consequências negativas da restrição do consumo desse recurso.

\section{Consumo de água e restrição hídrica}

A água é o nutriente mais importante e mais consumido pelas aves (VIOLA et al, 2011). A Tabela 01 apresenta o consumo de água ( $\mathrm{ml} / \mathrm{semana}$ ) por diferentes espécies de aves em diferentes idades. 
BARBOSA, T.M. et al. A importância da água na avicultura. PUBVET, Londrina, V. 8, N. 19, Ed. 268, Art. 1785, Outubro, 2014.

Tabela 01. Consumo de água de frangos de corte, aves de postura eperus em diferentes idades.

\begin{tabular}{cccccc}
\hline Idade & $\begin{array}{c}\text { Frangos de } \\
\text { corte }\end{array}$ & Postura leve & $\begin{array}{c}\text { Postura } \\
\text { pesada }\end{array}$ & \multicolumn{2}{c}{$\begin{array}{c}\text { Perus } \\
\text { (ml/semana) }\end{array}$} \\
(Semanas) & (ml/semana) & $(\mathrm{ml} /$ semana) & $(\mathrm{ml} /$ semana) & Machos & Fêmeas \\
\hline 1 & 225 & 200 & 200 & 385 & 385 \\
2 & 480 & 300 & 400 & 750 & 690 \\
3 & 725 & & & 1135 & 930 \\
4 & 1000 & 500 & 700 & 1650 & 1274 \\
5 & 1250 & & & 2240 & 1750 \\
6 & 1500 & 700 & 800 & 2870 & 2150 \\
7 & 1750 & & & 3460 & 2640 \\
8 & 2000 & 800 & 900 & 4020 & 3180 \\
9 & & & & 4670 & 3900 \\
10 & & 900 & 1000 & 5345 & 4400 \\
11 & & 1000 & 1100 & 6220 & 4660 \\
12 & & & &
\end{tabular}

Fonte: Adaptado de Bell \& Weaver (2002).

Segundo VIOLA et al. (2009) a restrição hídrica é um dos fatores que mais contribui para a queda de desempenho na produção avícola. Os mesmos autores ao avaliarem níveis crescentes de restrição hídrica (0\%, 10\%, 20\%, $30 \%$ e $40 \%$ ) observaram que a restrição promoveu uma diminuição linear no desempenho (Tabela 02). Ainda no mesmo estudo, os autores observaram a diminuição da altura das vilosidades duodenais dos frangos que sofreram restrição hídrica, além de se tornaram mais agressivos e irritadiços.

Segundo KIRKPATRICK \& FLEMING (2008) frangos consomem duas vezes mais água do que alimento, embora esta proporção possa ser maior em temperaturas elevadas. Os mesmos autores relatam que devido ao papel essencial que a água exerce na saúde e no desenvolvimento do organismo das 
BARBOSA, T.M. et al. A importância da água na avicultura. PUBVET, Londrina, V. 8, N. 19, Ed. 268, Art. 1785, Outubro, 2014.

aves, para se atingir um desempenho ótimo, é essencial fornecer, em qualquer fase da criação, água abundante, limpa, fresca e sem contaminantes químicos ou biológicos.

Tabela 02. Desempenho de frangos de corte sob restrição hídrica.

\begin{tabular}{|c|c|c|c|c|}
\hline Tratamento & & & & \\
\hline $\begin{array}{c}(\% \\
\text { restrição) }\end{array}$ & $\begin{array}{l}\text { Consumo } \\
\text { água (ml) }\end{array}$ & $\begin{array}{l}\text { Consumo } \\
\text { ração }(\mathrm{g})\end{array}$ & $\begin{array}{l}\text { Ganho de } \\
\text { peso }(\mathrm{g})\end{array}$ & $\begin{array}{c}\text { Conversão } \\
\text { alimentar }(\mathrm{g} / \mathrm{g})\end{array}$ \\
\hline $0 \%$ & 2295 & $1077 a$ & $823 a$ & $1,31 \mathrm{c}$ \\
\hline $10 \%$ & 2066 & $988 b$ & $697 b$ & $1,42 b$ \\
\hline $20 \%$ & 1836 & $877 c$ & $611 \mathrm{c}$ & $1,44 a b$ \\
\hline $30 \%$ & 1605 & $788 d$ & $517 d$ & $1,53 a$ \\
\hline $40 \%$ & 1377 & $697 e$ & $487 d$ & $1,43 a b$ \\
\hline
\end{tabular}

Médias, na mesma coluna, seguidas por letras diferentes são diferentes $(P<0,05)$ pelo teste Tukey. Fonte: Adaptado de Viola (2009).

Para um ganho de peso diário (GPD) de $55 \mathrm{~g}$, um frango armazena $38 \mathrm{~g}$ de água e $17 \mathrm{~g}$ de outros compostos (proteínas, gordura, minerais). Entretanto, para reter estas $38 \mathrm{~g}$ de água diárias, esta ave consumiu entre 75 a $115 \mathrm{~g}$ de água, ou seja, 2 a 3 vezes a ingestão de ração. Com base nestes dados, pode-se observar que a qualidade e a quantidade de água disponível para frangos de corte são de extrema importância (KRABBE \& ROMANI, 2013).

A Tabela 03 apresenta a relação entre o consumo de água/consumo de alimento, consumo de água/ganho de peso de frangos de corte até a terceira semana de vida observada por VIOLA (2003).

A água representa $85 \%$ do peso corporal de pintos (KIRKPATRICK \& FLEMING, 2008), 58 a 70\% do peso corporal de aves adultas e $65 \%$ do peso do ovo (GAMA et al., 2004). Segundo Vorha (1980) uma ave pode sobreviver até 30 dias sem alimento, suporta a perda de $98 \%$ da gordura e $50 \%$ da 
BARBOSA, T.M. et al. A importância da água na avicultura. PUBVET, Londrina, V. 8, N. 19, Ed. 268, Art. 1785, Outubro, 2014.

proteína do corpo, no entanto, morre quando perde $20 \%$ da água presente em seu organismo.

Tabela 03. Relação entre o consumo de água/consumo de alimento, consumo de água/ganho de peso de frangos de corte até aterceira semana de vida.

\begin{tabular}{lccc}
\hline & \multicolumn{3}{c}{ Semana } \\
& 1 & 2 & 3 \\
\hline Ganho de peso semanal $(\mathrm{g})$ & 140 & 284 & 398 \\
Consumo médio semanal $(\mathrm{g})$ & 173 & 542 & 1.077 \\
Consumo de água semanal & 319 & 1.024 & 2.295 \\
Consumo de água: ganho de peso $(\mathrm{ml} / \mathrm{g})$ & $2,28: 1$ & $3,60: 1$ & $5,76: 1$ \\
Consumo água: consumo de alimento & $1,84: 1$ & $1,88: 1$ & $2,13: 1$
\end{tabular}

Fonte: Adaptado de Viola (2003).

As aves consomem pequenas quantidades de água, porém com muita frequência, portanto deve ser garantido a elas um fornecimento constante de água (GAMA et al., 2004). O consumo de água é um ótimo indicador de bem estar e sanidade das aves, portanto, é de extrema importância que as empresas definam o consumo esperado de seus plantéis nas suas condições de produção e que monitorem constantemente este parâmetro (WATKINS \& TABLER, 2009).

Alterações bruscas no consumo de água requerem avaliação das causas, pois essas podem prejudicar o desempenho das aves, caso o consumo esteja aquém do esperado. Podem aumentar a umidade da cama, aumentando a incidência de pododermatite e de doenças respiratórias, caso o consumo ou o desperdício de água esteja além do esperado, podendo assim comprometer o bem estar das aves no plantel (MANNING et al., 2007). 
BARBOSA, T.M. et al. A importância da água na avicultura. PUBVET, Londrina, V. 8, N. 19, Ed. 268, Art. 1785, Outubro, 2014.

De acordo com KRABBE \& ROMANI (2013) a água consumida deve ficar em equilíbrio com as perdas, para que a desidratação e o decréscimo no desempenho não ocorram.

\section{Variáveis que interferem no consumo de água}

Entre os fatores mais significativos que interferem no consumo de água estão a genética, a idade do animal, o sexo, a temperatura do ambiente, a temperatura da água, a umidade relativa do ar e a composição nutricional do alimento (PENZ, 2003).

O consumo de água é diretamente relacionado com a idade das aves (Tabela 04); aves velhas consomem mais água que aves jovens, porém, quando determinado por unidade de peso vivo, o consumo de água/kg de peso vivo cai com o passar do tempo. Isso mostra o quanto a água é importante nas primeiras fases de desenvolvimento dos frangos (VIOLA, 2003).

Tabela 04. Consumo médio de água de frangos de corte de uma a três semanas de idade ( $\mathrm{ml} /$ ave).

\section{Dia da semana}

\begin{tabular}{cccccccc}
\hline Semana & 1 & 2 & 3 & 4 & 5 & 6 & 7 \\
\hline 1 & 23 & 33 & 40 & 53 & 57 & 57 & 55 \\
2 & 79 & 85 & 88 & 98 & 108 & 107 & 141 \\
3 & 137 & 163 & 164 & 194 & 190 & 225 & 198
\end{tabular}

Fonte: Viola (2003).

Aves do gênero macho consomem mais água do que as fêmea, desde o primeiro dia de vida (VIOLA et al., 2011). Entretanto esta diferença de consumo está relacionada com a diferença de peso das aves e também com a composição tecidual de cada sexo na mesma idade. Deve ser lembrado que 
BARBOSA, T.M. et al. A importância da água na avicultura. PUBVET, Londrina, V. 8, N. 19, Ed. 268, Art. 1785, Outubro, 2014.

quanto maior a deposição de tecido adiposo, menor é a deposição de água na carcaça. Além disso, os machos apresentam maior consumo de proteína, o que contribui para a maior necessidade de água (VIOLA et al., 2011; ZIAEI et al., 2007).

RIEK et al. (2008) observaram a influência do sexo quando analisaram o consumo de água de perus de 15 semanas de idade. Os machos consumiram aproximadamente $30 \%$ mais água que as fêmeas, $1.054 \mathrm{vs} 742 \mathrm{ml} / \mathrm{dia}$, respectivamente. No entanto, a influência significativa de sexo foi eliminada quando o total de água consumida foi expressa em $\mathrm{ml}$ por $\mathrm{kg}$ de peso vivo, 76 vs $70 \mathrm{ml} / \mathrm{kg}$ de peso vivo, machos vs fêmeas, respectivamente.

O impacto da temperatura ambiental é grande sobre o consumo de água, sendo que quanto maior a temperatura do ambiente, maior será o consumo de água, se esta estiver a uma temperatura menor que a ambiental (Figura 1) (KIRKPATRICK \&FLEMING, 2008).

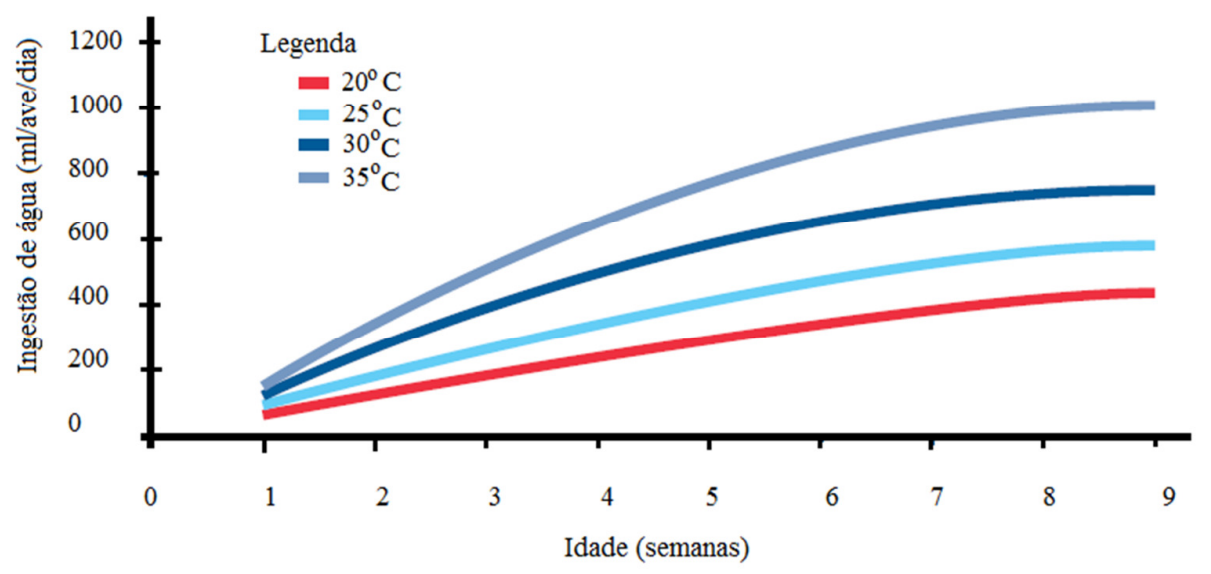

Figura 01. Efeito da temperatura ambiental sobre o consumo da água.

Fonte: Kirkpatrick\& Fleming (2008).

PENZ (2003) afirma que qualquer nutriente que promove um aumento na excreção de minerais pelos rins também promove um aumento de consumo de água. Segundo VIOLA et al. (2011) dietas com alta concentração de sódio 
BARBOSA, T.M. et al. A importância da água na avicultura. PUBVET, Londrina, V. 8, N. 19, Ed. 268, Art. 1785, Outubro, 2014.

ou potássio estão associadas com aumento de consumo de água; dietas com concentração de sódio de $0,25 \%$ estimulam aumento do consumo de água em $10 \%$ em comparação com dietas contendo $0,14 \%$ de sódio. Assim, a manipulação do conteúdo mineral da dieta é uma forma de prática de controle do consumo de água.

Os níveis de proteína da dieta também modificam o consumo de água; dietas com alta proteína proporcionam aumento no consumo de água, que pode estar relacionado ao mecanismo de excreção do ácido úrico pelos rins; em média aumentos de $1 \%$ na proteína da dieta estão associados com 3\% de aumento no consumo de água (VIOLA et al., 2011).

LIMA et al. (2011) avaliaram os efeitos da inclusão de níveis crescentes de sódio $(0,07 ; 0,12 ; 0,17 ; 0,22 ; 0,27$ e $0,32 \%)$ na ração da fase de crescimento sobre o desempenho de codornas japonesas nas fases de crescimento e de produção. O aumento de sódio na ração provocou aumento linear no consumo de água (Tabela 05).

Tabela 05. Desempenho de codornas de postura na fase decrescimento alimentadas com rações suplementadascomsódio.

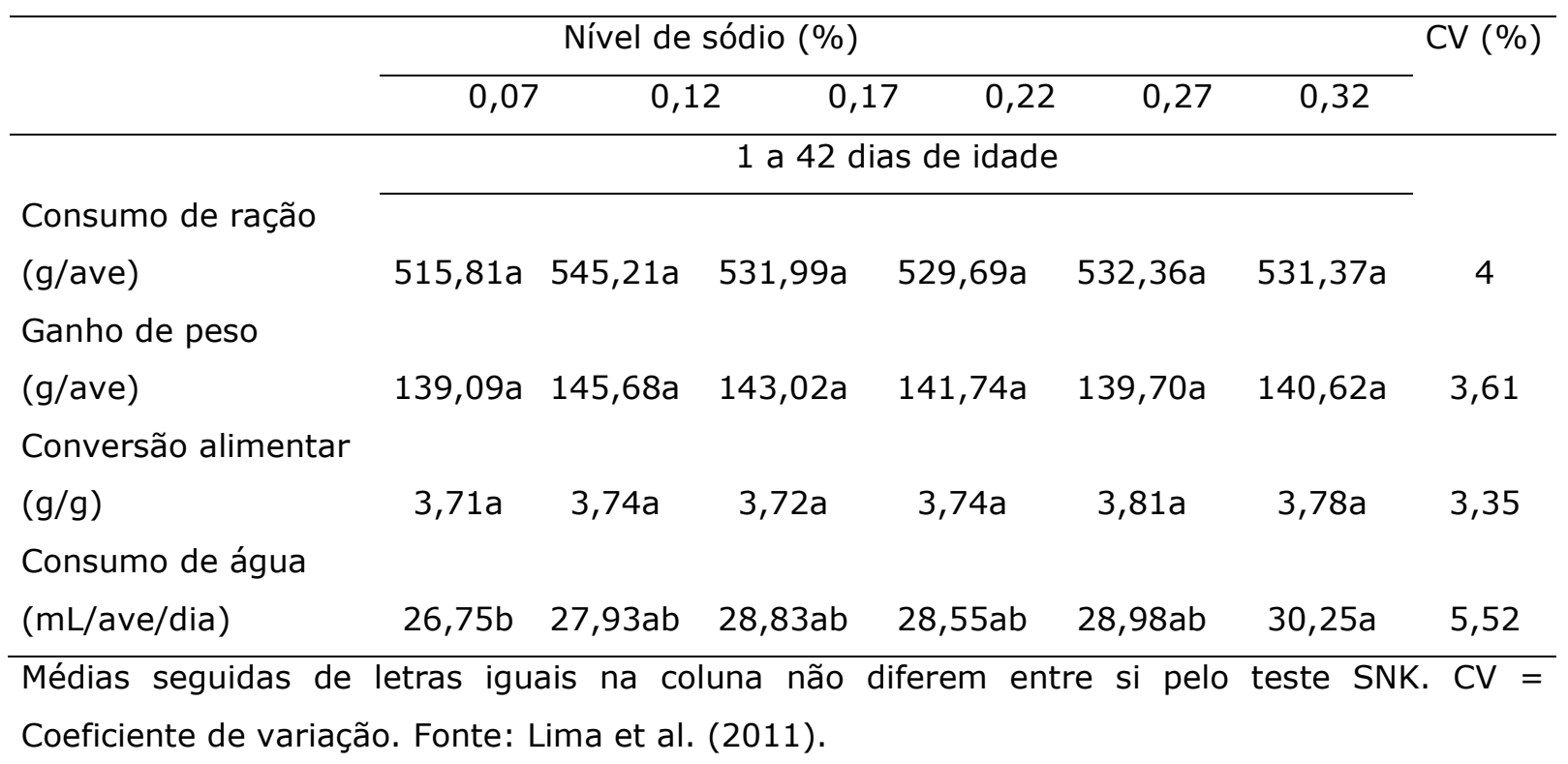


BARBOSA, T.M. et al. A importância da água na avicultura. PUBVET, Londrina, V. 8, N. 19, Ed. 268, Art. 1785, Outubro, 2014.

LIMA et al. (2011) também constataram que o aumento de sódio na ração causou aumento na umidade das excretas e efeito quadrático na digestibilidade de matéria seca, nitrogênio, energia bruta e nos valores de energia metabolizável aparente e aparente corrigida. De acordo com as equações obtidas na análise de regressão, a digestibilidade da matéria seca aumentou em até $0,20 \%$, e a do nitrogênio em até $0,27 \%$. Entretanto, os pesquisadores não observaram melhora no desempenho na fase de postura e concluíram que rações para codornas japonesas na fase de 1 a 42 dias devem ser formuladas com 0,12 a $0,23 \%$ de sódio.

RAQUEL et al. (2011) ao avaliarem os mesmos níveis de sódio estudados por LIMA et al. (2011) para codornas italianas destinadas à produção de carne também observaram o aumento na ingestão de água. Os níveis de sódio apresentaram efeito quadrático sobre o consumo de ração, o ganho de peso, os rendimentos de carcaça e coxa+sobrecoxa. Entretanto, a umidade das excretas e o rendimento de peito não foram afetados pelos níveis de sódio. Os autores recomendam que as rações para codornas italianas na fase de 1 a 49 dias sejam formuladas com $0,22 \%$ de sódio.

Segundo KRABBE\& ROMANI(2013) o tipo de bebedouro disponível para as aves é um importante fator que interfere no consumo de água. Os principais modelos de bebedouro no mercado são do tipo calha, pendular e nipple e independentemente do tipo, devem ser sempre mantidos limpos, com água fresca e em quantidades suficientes para atender à demanda dos animais.

A correta regulagem da altura é muito importante quando se usa bebedouros tipo calha ou pendular (KRABBE \& ROMANI, 2013). De acordo com KIRKPATRICK \& FLEMING (2008) bebedouros regulados baixos aumentam o desperdício e não permitem o consumo adequado, pois devido à ranhura no palato e pela anatomia do bico as aves não conseguem succionar a água. Por outro lado, bebedouros regulados altos dificultam a chegada dos frangos para posicionarem-se para beber, dificultando assim o consumo, pois os frangos não conseguem ver a água, especialmente os menores do lote. Estes autores 
BARBOSA, T.M. et al. A importância da água na avicultura. PUBVET, Londrina, V. 8, N. 19, Ed. 268, Art. 1785, Outubro, 2014.

recomendam que os bebedouros sejam regulados na altura da projeção do dorso das aves.

A quantidade de água dos bebedouros tipo calha ou pendular varia com a idade dos frangos; com o intuito de garantir o consumo de água na primeira semana de vida, os bebedouros devem ficar bem cheios, aproximadamente $90 \%$ de sua capacidade. Porém à medida que os frangos vão ficando mais velhos, para evitar o desperdício, a quantidade de água deve ser diminuída, até que aos 21 dias de idade a quantidade de água deve corresponder a 1/3 da capacidade dos bebedouros (PENZ, 2003).

Para evitar a restrição do consumo de água em bebedouros tipo nipple, a vazão deve ser aumentada constantemente; cada fabricante recomenda valores crescentes de vazão, de acordo com a idade dos frangos (Tabela 06). Este tipo de bebedouro deve ser ajustado de tal forma que, quando os frangos se posicionam para beber água, o ângulo da cabeça deve ficar em torno de $45^{\circ} \mathrm{e}$, para um perfeito controle de altura é necessário, antes do alojamento dos pintos, nivelar a cama abaixo das linhas dos nipples(KRABBE \& ROMANI, 2013; VIOLA et al., 2011).

Tabela 06. Idade e vazão de água de bebedouros tipo nipple.

\begin{tabular}{cc}
\hline Idade & Vazão (ml/min) \\
\hline 1 a 20 dias & 30 \\
21 a 35 dias & 60 \\
36 dias ao abate & $>90$ (ideal 130) \\
\hline
\end{tabular}

Fonte: Adaptado de Cobb-Vantres (2008).

Segundo VIOLA et al. (2011) há uma grande diferença no padrão de ingestão de água entre os tipos de bebedouros, os tipo nipple proporcionam um consumo menor em comparação com outros bebedouros. TOGASHIet al. (2008) observaram que bebedouros tipo taça resultaram em um consumo superior da ordem de $35 \mathrm{ml} / a v e / d i a$, comparados às aves que utilizavam 
BARBOSA, T.M. et al. A importância da água na avicultura. PUBVET, Londrina, V. 8, N. 19, Ed. 268, Art. 1785, Outubro, 2014.

bebedouros tipo nipple (Tabela 07). Porém o uso de bebedouro tipo nipplepossibilita o fornecimento de água com melhor qualidade microbiológica para poedeiras e, consequentemente, favorece o melhor desempenho das aves. A produção de ovos aumentou e a conversão alimentar diminuiu, significativamente, nas aves que receberam água por bebedouros tipo nipple (Tabela 08).

Tabela 07. Médias semanais do consumo de água em poedeirascriadas com dois tipos de bebedouros.

\begin{tabular}{ccc}
\hline Semana & \multicolumn{2}{c}{ Consumo de água (ml/ave/dia) } \\
\cline { 2 - 3 } & Taça & Nipple \\
\hline 1 & 241 & 210 \\
2 & 255 & 215 \\
3 & 223 & 191 \\
4 & 232 & 190 \\
5 & 220 & 198 \\
6 & 232 & 185 \\
7 & 233 & 207 \\
8 & 238 & 208 \\
9 & 252 & 206 \\
Média & 236 & 201 \\
\hline
\end{tabular}

Fonte: Adaptado de Togashiet al (2008).

Tabela 08. Desempenho de poedeiras comerciais criadas com doistipos de bebedouro.

\begin{tabular}{lccc}
\hline Variável & \multicolumn{2}{c}{ Bebedouro } & CV(\%) \\
\cline { 2 - 3 } & Taça & Nipple & \\
\hline Consumo de ração (g/ave/dia) & $102,90 \mathrm{a}$ & $105,08^{\mathrm{a}}$ & 4,00 \\
Porcentagem de postura (\%) & $92,80 \mathrm{~b}$ & $97,72^{\mathrm{a}}$ & 4,17 \\
Massa de ovo (g/ave/dia) & $56,20 \mathrm{~b}$ & $58,90^{\mathrm{a}}$ & 3,35 \\
Conversão alimentar $(\mathrm{kg} / \mathrm{kg})$ & $1,83 \mathrm{~b}$ & $1,78^{\mathrm{a}}$ & 3,50 \\
\hline
\end{tabular}

Médias nas linhas, seguidas de letras diferentes $(P<0,05)$ estatisticamente pelo teste F.CV = Coeficiente de variação. Fonte: Togashiet al (2008). 
BARBOSA, T.M. et al. A importância da água na avicultura. PUBVET, Londrina, V. 8, N. 19, Ed. 268, Art. 1785, Outubro, 2014.

\section{Estresse calórico $\mathrm{x}$ ingestão de água}

A rápida evolução da avicultura resultou na seleção genética de um frango de corte precoce e com grande eficiência para converter proteína vegetal em proteína animal. Contudo, muitos problemas metabólicos e de manejo têm surgido, destacando-se entre eles o estresse calórico (WATKINS, 2000).

A susceptibilidade das aves ao estresse calórico aumenta à medida que o binômio umidade relativa e temperatura ambiente ultrapassam a zona de conforto térmico, dificultando assim a dissipação de calor, incrementando consequentemente a temperatura corporal da ave, com efeito negativo sobre o desempenho (FURLAN, 2006). Para minimizar as perdas decorrentes do estresse calórico algumas medidas podem ser tomadas como a utilização de ventiladores e nebulizadores, manipulação da proteína e energia da dieta, aclimatação das aves, utilização de antitérmicos, ácido ascórbico, eletrólitos, manejo do arraçoamento e o manejo da água de bebida (BORGES et al., 2003).

As aves, por serem animais homeotermos, dispõem de um centro termorregulador, localizado no hipotálamo, capaz de controlar a temperatura corporal através de mecanismos fisiológicos e respostas comportamentais, mediante a produção e liberação de calor, determinando assim a manutenção da temperatura corporal normal que é $41,1^{\circ} \mathrm{C}$ (MACARI \& SOARES, 2012).

A vasodilatação periférica é uma resposta fisiológica compensatória das aves, que resulta no aumento da perda de calor não evaporativo quando expostas ao calor. Na tentativa de aumentar a dissipação do calor, a ave consegue aumentar a área superficial, mantendo as asas afastadas do corpo, eriçando as penas e intensificando a circulação periférica. A perda de calor não evaporativo pode também ocorrer com o aumento da produção de urina, se esta perda de água for compensada pelo maior consumo de água fria (BORGES et al., 2003). 
BARBOSA, T.M. et al. A importância da água na avicultura. PUBVET, Londrina, V. 8, N. 19, Ed. 268, Art. 1785, Outubro, 2014.

O alto calor específico da água (a energia calórica necessária para aumentar $1^{\circ} \mathrm{C}$ a temperatura de um grama de água) é útil para as células e organismos, porque possibilita que a água atue como "tampão de calor", permitindo que a temperatura de um organismo permaneça relativamente constante, mesmo quando a temperatura do ar flutue e que o calor seja gerado em quantidades relativamente grandes como um subproduto do metabolismo (MACARI \& SOARES, 2012).

As aves possuem reduzida capacidade de transpirar, pois não possuem glândulas sudoríparas, por isso as perdas por evaporação pela pele são pouco significativas, portanto as perdas evaporativas através da respiração são muito importantes (VIOLA et al., 2011).

A alta condutividade térmica, o alto calor específico, e o alto calor latente de vaporização permitem o acúmulo e a transferência de calor pela perda evaporativa, que são propriedades físicas da água, importantes na regulação da temperatura corporal (VIOLA et al., 2011).

O resfriamento evaporativo respiratório constitui-se em um dos mais importantes meios de perda de calor das aves em temperaturas elevadas. Isto porque, as aves têm a capacidade de aumentar a frequência respiratória em até 10 vezes e, desta forma aumentar a perda de calor no trato respiratório (FURLAN, 2006). De acordo com o mesmo autor, para a evaporação $1 \mathrm{~g}$ de água são necessárias 550 calorias; assim, quanto maior a frequência respiratória do frango, maior quantidade de calor é dissipada para o meio ambiente.

MACARI \& SOARES (2012) citam em seu livro que LEESON \& SUMMERS (1997) indicaram que a perda total de calor corporal por evaporação representa $12 \%$ do total, em frangos mantidos em ambiente com $10^{\circ} \mathrm{C}$. Porém, essa perda pode chegar até $50 \%$, quando a temperatura do ambiente for de 26 a $35^{\circ} \mathrm{C}$.

De acordo com FURLAN (2006) existe uma estreita relação entre umidade do ar e temperatura, no que se refere ao conforto térmico das aves. 
BARBOSA, T.M. et al. A importância da água na avicultura. PUBVET, Londrina, V. 8, N. 19, Ed. 268, Art. 1785, Outubro, 2014.

Um grau de umidade elevado torna as aves mais sensíveis ao estresse por calor, pela dificuldade de perda de calor por evaporação. A Tabela 09 mostra o efeito da temperatura e umidade relativa do ar sobre a dissipação de calor pelo processo evaporativo em frangos de corte.

Tabela 09. Efeito da temperatura e umidade relativa do ar sobre a dissipação de calor pelo processo evaporativo nos frangosde corte (\% do total).

\begin{tabular}{ccc}
\hline Temperatura $\left({ }^{\circ} \mathrm{C}\right)$ & Umidade Relativa $(\%)$ & Perda por Evaporação \\
\hline 20 & 40 & 25 \\
20 & 87 & 25 \\
24 & 40 & 50 \\
24 & 84 & 22 \\
34 & 40 & 80 \\
34 & 90 & 39 \\
\hline
\end{tabular}

Fonte: Furlan (2006).

O aumento na taxa respiratória resulta em perdas excessivas de dióxido de carbono $\left(\mathrm{CO}_{2}\right)$. Assim, a pressão parcial de $\mathrm{CO}_{2}\left(\mathrm{pCO}_{2}\right)$ diminui, levando à queda na concentração de ácido carbônico $\left(\mathrm{H}_{2} \mathrm{CO}_{2}\right)$ e hidrogênio $\left(\mathrm{H}^{+}\right)$. Em resposta, os rins aumentam a excreção de $\mathrm{HCO}_{3}{ }^{-}$e reduzem a excreção de $\mathrm{H}^{+}$ na tentativa de manter o equilíbrio ácido-base da ave. Esta alteração do equilíbrio ácido-base é denominada de alcalose respiratória e precisa ser corrigida o mais rápido possível, pois causa queda no desempenho das aves (BORGES, 2003).

A quantidade de água ingerida pelas aves aumenta com a elevação da temperatura ambiente. Portanto, o consumo de água durante o estresse calórico é limitante para a taxa de crescimento e sobrevivência, isto porque, durante o estresse calórico a água tem papel fundamental nos mecanismos refrigeradores envolvidos na termorregulação das aves. Assim sendo, são necessários cuidados especiais de manejo durante o estresse, principalmente 
BARBOSA, T.M. et al. A importância da água na avicultura. PUBVET, Londrina, V. 8, N. 19, Ed. 268, Art. 1785, Outubro, 2014.

os associados com a qualidade e a temperatura da água, uma vez que as evidências sugerem que o aumento no consumo de água beneficia a ave, ao atuar como um tampão de calor (FURLAN, 2006). A Tabela 10 mostra a ingestão diária de água em diferentes temperaturas e tipos de aves.

Tabela 10. Ingestão diária (litros/1000 aves) de água em diferentes temperaturas e tipo de aves.

\begin{tabular}{lccc}
\hline Ave & Idade (semanas) & \multicolumn{2}{c}{ Ingestão de água } \\
\cline { 3 - 4 } & & 20 & Temperatura Ambiente $\left({ }^{0} \mathrm{C}\right)$ \\
\cline { 3 - 4 } Franga Leghorn & 4 & 50 & 32 \\
& 12 & 115 & 190 \\
& 18 & 140 & 220 \\
Poedeiras & $50 \%$ de Produção & 180 & 340 \\
& $90 \%$ de Produção & 200 & 400 \\
& $0 \%$ de Produção & 150 & 250 \\
Frangos de Corte & 1 & 24 & 50 \\
& 3 & 100 & 210 \\
& 6 & 280 & 600
\end{tabular}

Fonte: Adaptado de Leeson\& Summers (1991).

Considerando que a ave dissipa calor ao consumir água, esta deverá apresentar-se com temperaturas inferiores à temperatura corporal, sendo mais eficiente quanto maior for esta diferença. Neste sentido, cuidados devem ser tomados para que o reservatório de água seja colocado em local fresco (FURLAN, 2006).

De acordo com MACARIet al. (1994), quando em situações de estresse, a temperatura da água deve estar ao redor de $20^{\circ} \mathrm{C}$, para auxiliar na redução da 
BARBOSA, T.M. et al. A importância da água na avicultura. PUBVET, Londrina, V. 8, N. 19, Ed. 268, Art. 1785, Outubro, 2014.

temperatura corporal. TEETER (1994) mostrou que quando administrada a frangos de corte sob estresse calórico, a água (30 $\mathrm{ml} / \mathrm{Kg}$ de peso vivo) aquecida até a temperatura corporal, não apresentou nenhum impacto sobre a temperatura corporal; ao passo que foi obtida uma diminuição de $1^{\circ} \mathrm{C}$ na temperatura corporal quando a água administrada tinha uma temperatura de $12,7^{\circ} \mathrm{C}$.

SINGLETON et al. (2004) observaram que após $20^{\circ} \mathrm{C}$, para cada $1^{\circ} \mathrm{C}$ que a temperatura ambiental aumentou, o consumo de água aumentou em $6 \%$, enquanto que o consumo de ração diminuiu em 1,23\%. 0 organismo das aves tem adaptações específicas em consonância com as alterações cardiorrespiratórias e metabólicas ante o estresse calórico. Essas modificações estão associadas à preservação da água corporal perdida na tentativa de manter o resfriamento evaporativo e o volume sanguíneo, para suportar o aumento no débito cardíaco induzido pela vasodilatação periférica no calor (MACARI \& SOARES, 2012).

A perda de água é tanto maior quanto menor a idade do frango de corte, quando da exposição ao estresse calórico. Pintinhos de 7 dias perderam até $12 \%$ de peso corporal. Já, em frangos de corte com 42 dias, a perda foi ao redor de $4,5 \%$ do peso corporal, quando submetidos ao estresse calórico agudo. Estes dados só reforçam a tese da necessidade de cuidados especiais que devem ser tomados quando do alojamento dos pintinhos, pois o excesso de calor, através das campânulas, pode provocar desidratação com aumento da taxa de mortalidade ou refugagem do lote (FURLAN, 2006).

SEVEGNANI et al. (2005) ao estudar o comportamento junto ao bebedouro de frangos de corte de diferentes idades, pôde observar que, pela necessidade de refrigerar o organismo, quanto mais quente e úmido e quanto mais velha a ave, maior foi o tempo gasto na ingestão de água, o oposto do que ocorreu com o tempo gasto no comedouro.

Durante o estresse calórico as aves ingerem mais água, portanto há maior excreção renal, caracterizada pelo aumento do volume urinário. Além do 
BARBOSA, T.M. et al. A importância da água na avicultura. PUBVET, Londrina, V. 8, N. 19, Ed. 268, Art. 1785, Outubro, 2014.

volume de água, a temperatura ambiente também influencia a perda urinária de minerais (eletrólitos). Os eletrólitos sódio $(\mathrm{Na})$, potássio $(\mathrm{K})$ e cloro $(\mathrm{Cl})$, juntamente com cálcio ( $\mathrm{Ca})$, magnésio $(\mathrm{Mg})$, fosfatos, sulfato e bicarbonato participam da manutenção do $\mathrm{pH}$ sanguíneo e do equilíbrio osmótico. O balanço eletrolítico, além de ser importante para a manutenção do equilíbrio ácido-básico, é necessário para proporcionar o crescimento muscular, desenvolvimento ósseo, utilização de aminoácidos, eficiência alimentar, resposta imune e sobrevivência no estresse calórico (MACARI \& SOARES, 2012).

Muitas pesquisas foram realizadas utilizando diferentes sais, no intuito de avaliar os efeitos negativos das altas temperaturas sobre o desempenho e a sobrevivência de aves. A suplementação desses sais tem sido usada para aumentar o consumo de água bem como para aumentar a ingestão de íons específicos, prevendo mudanças no equilíbrio acido básico, não interferindo no ganho de peso e na sobrevivência das aves (MACARI \& SOARES, 2012).

A utilização de sais via água de bebida ou ração é uma alternativa frequentemente empregada pelos produtores de frangos de corte para reduzir as perdas decorrentes do estresse calórico. Entre os principais sais utilizados destacam-se o cloreto de potássio $(\mathrm{KCl})$ e o bicarbonato de sódio $\left(\mathrm{NaHCO}_{3}\right)$ (BORGES, 2003).

AHMAD et al. (2008) observaram efeito benéfico com a suplementação de $0,6 \%$ de $\mathrm{KCl}$ na água de bebida, observaram a redução significativa do $\mathrm{pH}$ sanguíneo (de 7,40 para 7,31) em aves de 42 dias de idade submetidas ao estresse calórico.

SOUSA (2006) ao avaliar a suplementação de bicarbonato de sódio associado ao cloreto de amônio, em 6 diferentes níveis, não observou diferenças nos parâmetros de desempenho, na relação consumo de água/consumo de ração, na temperatura retal, nas características de carcaça e não influenciou a umidade da cama, porém, diminuiu a mortalidade e aumentou o consumo de água dos frangos de corte criados sob condições 
BARBOSA, T.M. et al. A importância da água na avicultura. PUBVET, Londrina, V. 8, N. 19, Ed. 268, Art. 1785, Outubro, 2014.

naturais de estresse calórico, no período de 22 a 42 dias de criação (Tabela 11). SALVADOR (1999) salienta que deve-se ter cuidado na utilização do bicarbonato, pois a adição de altas concentrações pode induzir alcalose metabólica, acentuando o problema de alcalose respiratória das aves quando estressadas pelo calor.

Tabela 11. Consumo de ração, consumo de água, consumo de água/consumo de ração, mortalidade (MT) e viabilidade (VB) de frangos de corte suplementados com bicarbonato de sódio associado ao cloreto de amônio na ração no período de 22 a 42 dias de criação.

\begin{tabular}{cccccc}
\hline Tratamentos & $\begin{array}{c}\text { Consumo de ração } \\
\text { (g/ave/dia) }\end{array}$ & $\begin{array}{c}\text { Consumo de água } \\
(\mathrm{ml} / \text { ave/dia })\end{array}$ & $\begin{array}{c}\text { Consumo de água/ } \\
\text { consumo de ração } \\
(\mathrm{ml} / \mathrm{g})\end{array}$ & $\begin{array}{c}\text { MT } \\
(\%)\end{array}$ & $\begin{array}{c}\text { VB } \\
(\%)\end{array}$ \\
\hline T1 & 141,65 & $39,18^{\mathrm{A}}$ & 2,75 & 4,15 & 95,85 \\
T2 & 145,88 & $430,60^{\mathrm{AB}}$ & 2,96 & 0,0 & 100 \\
T3 & 150,20 & $451,58^{\mathrm{B}}$ & 3,00 & 0,0 & 100 \\
T4 & 149,36 & $461,95^{\mathrm{B}}$ & 3,08 & 2,09 & 97,91 \\
T5 & 150,97 & $453,46^{\mathrm{B}}$ & 3,00 & 0,0 & 100 \\
T6 & 147,80 & $466,0^{\mathrm{B}}$ & 3,15 & 0,0 & 100 \\
T7 & 148,50 & $474,15^{\mathrm{B}}$ & 3,20 & 0,0 & 1000 \\
T8 & 147,40 & $458,25^{\mathrm{B}}$ & 3,11 & 0,0 & 1000 \\
T9 & 146,33 & $458,93^{\mathrm{B}}$ & 3,14 & 0,0 & 100 \\
T10 & 149,34 & $457,28^{\mathrm{B}}$ & 3,06 & 2,1 & 97,91 \\
\hline Médias & $147,74^{\mathrm{A}}$ & $450,24^{\mathrm{AB}}$ & $3,04^{\mathrm{A}}$ & & \\
\hline (CV \%) & 4,38 & $5,6^{\mathrm{B}}$ & 8,74 & &
\end{tabular}

Tratamentos :T1 = 0,0\% NaHCO3 + 0,0\% NH4Cl; T2 = 0,3\% NaHCO3 + 0,2\% NH4Cl; $\mathrm{T} 3=$ $0,3 \% \mathrm{NaHCO} 3+0,4 \% \mathrm{NH} 4 \mathrm{Cl} ; \mathrm{T} 4=0,3 \% \mathrm{NaHCO} 3+0,6 \% \mathrm{NH} 4 \mathrm{Cl} ; \mathrm{T} 5=0,6 \% \mathrm{NaHCO} 3+$ $0,2 \% \mathrm{NH} 4 \mathrm{Cl} ; \mathrm{T} 6=0,6 \% \mathrm{NaHCO} 3+0,4 \% \mathrm{NH} 4 \mathrm{Cl} ; \mathrm{T} 7=0,6 \% \mathrm{NaHCO} 3+0,6 \% \mathrm{NH} 4 \mathrm{Cl} ; \mathrm{T} 8=$ $0,9 \% \mathrm{NaHCO} 3+0,2 \% \mathrm{NH} 4 \mathrm{Cl} ; \mathrm{T} 9=0,9 \% \mathrm{NaHCO} 3+0,4 \% \mathrm{NH} 4 \mathrm{Cl} ; \mathrm{T} 10=0,9 \% \mathrm{NaHCO} 3+$ $0,6 \% \mathrm{NH} 4 \mathrm{Cl}$.

Médias na mesma variável, seguidas de letras diferentes, na coluna, diferem $(P<0,05)$ entre si pelo teste F. CV = Coeficiente de variação. Fonte: Sousa (2006). 
BARBOSA, T.M. et al. A importância da água na avicultura. PUBVET, Londrina, V. 8, N. 19, Ed. 268, Art. 1785, Outubro, 2014.

\section{Considerações finais}

A água é um nutriente indispensável para a vida, tendo em vista as funções que exerce no organismo. Por esta razão esse nutriente deve estar sempre disponível em quantidades suficientes para atender à demanda das aves.

Pelo fato de as aves não possuírem glândulas sudoríparas para atuarem na dissipação de calor, o consumo de água fria constituí alternativa para aves em situações de estresse calórico para a redução da temperatura corporal. A utilização de sais via água de bebida também se constitui uma alternativa frequentemente empregada pelos produtores para amenizar as alterações metabólicas decorrentes do estresse calórico.

A restrição hídrica é um dos fatores que mais contribui para a queda de desempenho na produção avícola, devido ao papel essencial que a água exerce na saúde e no desenvolvimento do organismo das aves, para se atingir um desempenho ótimo, é essencial fornecer, em qualquer fase da criação, água abundante, limpa e fresca.

\section{Referências}

1. AHMAD, T.; KHALID, T.; MUSHTAQ, T.; MIRZA, M.A; A. NADEEM, A.; BABAR, M. E.; AHMAD, G. Effect of Potassium Chloride Supplementation in Drinking Wateron Broiler Performance Under Heat Stress Conditions.Poultry Science v.87, n.7, p.1276-1280, 2008.

2. AMARAL, L. A. Drinking Water as a Risk Factor to Poultry Health. BrazilianJournalofPoultry Science, v. 6, n.4, p.191-199, 2004.

3. BeLlAVER, C.; OLIVEIRA, P.A. Balanço de água nas cadeias de aves e suínos. Avicultura Industrial, v. 10, p.39-44, 2009.

4. BORGES, A.S.; ALEX MAIORKA, A.; SILVA, A.V.F. Fisiologia do estresse calórico e a utilização de eletrólitos em frangos de corte. Ciência Rural, Santa Maria, v.33, n.5, p.975$981,2003$.

5. COBB-VANTRES. Broiler Management Guide.Cobb-Vantres. 62p., 2008.

6. FURLAN, R. L. Influência da temperatura na produção de frangos de corte. VII Simpósio Brasil sul de Avicultura - Chapecó, SC - Brasil, p.104-135, 2006. 
7. GAMA, N.M.S.Q; GUASTALLI, E.A.L; AMARAL, L.A; FREITAS, E.R; PAULILLO, A. C. Parâmetros químicos $e$ indicadores bacteriológicos daÁgua utilizada na dessedentação de aves nasGranjas de postura comercial. Arquivo InstitutoBiológico, São Paulo, v.71, n.4, p.423-430, 2004.

8. GAMA, N.M.S.Q; TOGASHI, C.K; FERREIRA, N.T; BUIM, M.R; GUASTALLI, E.L; FIAGÁ, D.A.M.Conhecendo a água utilizada para as aves de produção. Divulgação técnica: Instituto Biológico, Centro Avançado de Pesquisa Tecnológica do Agronegócio Avícola, Unidade de Pesquisa e Desenvolvimento de Bastos, São Paulo, v.70, n.1, p.43-49, 2008.

9. KIRKPATRICK, K; FLEMING, E. Calidad del agua.ROSS TECH NOTE 08/47. Febrero, 12p., 2008.

10. KRABBE, E; ROMANI, A.Importância da qualidade e do manejo da água na produção de frangos de corte. XIV Simpósio Brasil Sul de Avicultura e V Brasil Sul Poultry Fair Chapecó, SC - Brasil, p.113-121, 2013.

11. LIMA, R.C.; FREITAS, E.R.; RAQUEL, D.L; SÁ, N.L; LIMA,C.A.; PAIVA, A. C. Níveis de sódio para codornas japonesas na fase de crescimento. Revista Brasileira de Zootecnia, v.40, n.2, p.352-360, 2011.

12. MACARI, M. FURLAN, R.L., GONZALES, E. Fisiologia aviária aplicada a frangos de corte. FUNEP/UNESP, Jaboticabal, São Paulo, 296p., 1994.

13. MACARI, M.; SOARES, N.M. Água na avicultura industrial. Campinas: Fundação APINCO de Ciência e Tecnologia Avícolas, 359p.,2012.

14. MANNING, L.; CHADD, S.A.; BAINES, R.N. Water consumption in broiler chicken: a welfare indicator. World'sPoultry ScienceJournal, v.63, n.1 p.63-71, 2007.

15. OLIVEIRA, M.V.A.M. Recursos hídricos e a produção animal - legislação e aspectos gerais.Simpósio Produção Animal E Recursos Hídricos, Concórdia, Sc - Brasil, p.1-7, 2010.

16. PENZ, A.M. JR.Importância da água na produção deFrangos de corte. IV SIMPÓSIO BRASIL SUL DE AVICULTURA -Chapecó, SC - Brasil, p.112-131, 2003.

17. RAQUEL, D.L; LIMA, R.C.; FREITAS, E.R.; SÁ, N.L; LIMA,C.A.; PAIVA, A.C. Níveis de sódio para codornas italianas destinadas à produção de carne. Revista Brasileirade Zootecnia, v.40, n.1, p.135-141, 2011.

18. RIEK, A.; GERKEN, M.; WERNER, C.; GONDE, A. Deuterium for estimating total body water and turnover rates in turkeys exposed to different incubation treatments. Poultry Science, v.87, n.12, p.2624-2628, 2008.

19. SALVADOR, D.; ARIKI, J.; BORGES, S.A; PEDROSO, A.A; MORAES, V.M.B.Suplementação de bicarbonato de sódio na ração e na água de bebida de frangos de corte submetidos ao estresse calórico. ARS VETERINARIA, v.15, n.2, p.144-148, 1999.

20. SEVEGNANI, K.B.; CARO, I.W.; PANDORFI, H.; SILVA, I.J.O.; MOURA, D.J. Zootecnia de precisão: análise de imagens no estudo do comportamento de frangos de corte em estresse térmico.Revista Brasileira de Engenharia Agrícola e Ambiental, v.9, n.1, p.115-119, 2005.

21. SINGLETON, R. Hot weather broiler and breeder management. AsianPoultry Magazine, p.26-29, 2004. 
22. SOARES, N.M. Quantidade e qualidade da água na produção de aves. Simpósio produção animal e recursos hídricos, Concórdia, SC - Brasil, p.46-56, 2010.

23. SOUSA, F.N. Bicarbonato de sódio associado ao cloreto de amônio em rações para frangos de corte sob condições naturais de estresse calórico. Dissertação Mestrado Centro de Ciências Agrárias, da Universidade Federal do Piauí, 100p.,2006.

24. TEETER, R.G. Optimizing production of heat stressed broilers.PoultryDigest, v.53, p.10-27, 1994.

25. TOGASHI, C.K; ANGELA, H.L; FREITAS, E.R; GUASTALLI, E.A.L; MARCOS ROBERTO BUIM, M.R; GAMA, N.M.S.Q. Efeitos do tipo de bebedouro sobre a qualidade da água e o desempenho e a qualidade dos ovos de poedeiras comerciais. Revista Brasileira de Zootecnia, v.37, n.8, p.1450-1455, 2008.

26. VIOLA, E.S.; VIOLA, T.H.; LIMA,G. J.M.M; AVILA, V.S. Água na avicultura: importância, qualidade e exigências. Em: Manejo Ambiental na Avicultura. Disponível em: cnpsa.embrapa.br/sgc/sgc_publicacoes/publicacao_s3v74t2l.pdf. Acesso em 09/05/2013. EMBRAPA. Série documentos 149, p.37-123, 2011.

27. VIOLA, T.H. A influência da restrição da água no desempenho de frangos de corte. Dissertação (Mestrado) - Programa de Pós-Graduação em Zootecnia, Faculdade de Agronomia, Universidade Federal do Rio Grande do Sul, Porto Alegre, 150p., 2003.

28. VIOLA, T.H; RIBEIRO, A. M. L; PENZ JR, A. M ; VIOLA E. S. Influence of water restriction on the performance and organ development of young broilers.RevistaBrasileira de Zootecnia, v.38, n.2, p.323-327, 2009.

29. VOHRA, N.P. Water quality for poultry use. Feedstuffs, v.7, p.24-25, 1980.

30. WATKINS, S. Waterquality can influencepoultry performance. AvianAdvise, v. 2, n.2, p.11-12, 2000.

31. WATKINS. S.; TABLER, G.T. Broiler water consumption. Acesso em: 26/05/2013. Disponível em :http://www.avianadvice.uark.edu/AA\%20PDFs/avianadvice_Vol11No2.pdfAvianAdvice, v.11, n.2,p.11-12, 2009.

32. ZIAEI, N.; GUY, J.H; EDWARDS, S. A; BLANCHARD, P.J.; WARD, J.; FEUERSTEIN, D. Effect of Gender on Factors Affecting Excreta Dry Matter Content of Broiler Chickens.Journalof Applied Poultry Research, v.16, p.226-233, 2007. 